(1)

CrossMark

\title{
Detrimental effects of air pollution on adult lung function
}

\author{
Edith B. Milanzi and Ulrike Gehring
}

Affiliation: Institute for Risk Assessment Sciences (IRAS), Utrecht University, Utrecht, The Netherlands.

Correspondence: Ulrike Gehring, Utrecht University, Institute for Risk Assessment Sciences, PO Box 80178, 3508 TD Utrecht, The Netherlands. E-mail: u.gehringduuu.nl

@ERSpublications

Air pollution exposure may lead to lower lung function and higher risk of chronic obstructive pulmonary disease in adults http://bit.ly/2IpGx9j

Cite this article as: Milanzi EB, Gehring U. Detrimental effects of air pollution on adult lung function. Eur Respir J 2019; 54: 1901122 [https://doi.org/10.1183/13993003.01122-2019].

Air pollution, including ambient and household air pollution, is considered one of the world's largest environmental health threats and was estimated to account for 4.9 million deaths and 147 million years of healthy life lost around the world in 2017 [1]. Compelling evidence for adverse effects of air pollution on a vast array of health outcomes, in particular cardiovascular and respiratory health, has been established $[2,3]$.

Ambient air pollution has been shown to adversely affect lung function throughout the course of life. Many cross-sectional studies and several longitudinal studies have reported lower lung function and slower lung function growth as a result of exposure to air pollution in children [4-6] and adolescents [7-9]. Fewer studies have assessed associations of air pollution with lung function in adults, but increasing evidence from individual cohort studies from Europe [10-12], the USA [13] and Asia [14], as well as a recent multi-cohort study of five European cohorts within the European Study of Cohorts for Air Pollution Effects (ESCAPE) project [15], suggest adverse effects on adult lung function, too. Studies of effects of air pollution on lung function decline in adulthood are scarce and findings are mixed. An accelerated age-related decline in lung function among persons with higher exposure to air pollution was reported by a large study in Asia [14], but not in an ESCAPE multi-cohort study [15]. Additional evidence comes from cohort studies that reported slower declines in lung function in relation to reductions in air pollution exposure $[13,16]$.

Although our understanding of the long-term effects of air pollution on lung function has improved in recent years, the role of air pollution in chronic obstructive pulmonary disease (COPD) development is still unclear. COPD is an inflammatory airway disease that affects the small airways [17] and is characterised by progressive and not fully reversible airflow limitation [18]. It is the fourth leading cause of death worldwide, and has been predicted to become the third leading cause by 2030 [19], making it a major public health concern. Since COPD risk is jointly determined by lung growth during childhood and adolescence leading to the maximally attained level of lung function in early adulthood as well as the timing and rate of decline of lung function later in life [20], and these have been shown to be associated with air pollution, a link between air pollution exposure and COPD development seems plausible, but is not well investigated [21]. Evidence from the few studies that investigated this link directly across Europe as well as other geographical settings [14, 21-23] is suggestive, but not conclusive.

In this issue of the European Respiratory Journal, DorRon et al. [24] explored associations of long-term air pollution exposure with lung function and COPD in adults aged 40-69 years. The study is unique, with a 
sample size of 303887 participants, largely from urban areas of England, Wales and Scotland, within the UK Biobank National Cohort Study. In this study, higher levels of land use regression (LUR)-based estimates of air pollutants (nitrogen dioxide $\left(\mathrm{NO}_{2}\right)$, particulate matter with aerodynamic diameters $<10 \mu \mathrm{m}$ (PM10) and <2.5 $\mu \mathrm{m}$ (PM2.5), and between $2.5 \mu \mathrm{m}$ and $10 \mu \mathrm{m}$ (PMcoarse)) at participants' baseline (2006-2010) home address, were associated with lower pre-bronchodilation spirometry metrices of forced expiratory volume in $1 \mathrm{~s}(\mathrm{FEV} 1)$ and forced vital capacity (FVC), a lower FEV1/FVC ratio and a higher risk of COPD (defined as FEV1/FVC less than the lower limit of normal). Findings of this study corroborate findings of previous research suggesting that adults exposed to higher concentrations of air pollution experience significant reductions in lung function and have a higher risk of COPD.

Placing the findings by DorRon et al. [24] into perspective by comparing absolute changes in lung function for standardised exposure increments of the ESCAPE study, the observed association estimates are larger than those reported from studies that used similar exposure assessment methods, i.e. LUR models from the ESCAPE project. For example, for a $10 \mu \mathrm{g} \cdot \mathrm{m}^{-3}$ increase in $\mathrm{NO}_{2}$, ADAM et al. [15] reported a $13.9 \mathrm{~mL}$ (95\% CI -25.8 to $-2.1 \mathrm{~mL}$ ) reduction in FEV1, and DE Jong et al. [11] reported a $18 \mathrm{~mL}$ (95\% CI -30 to $-7 \mathrm{~mL}$ ) reduction in $\mathrm{FEV} 1$, whereas Dorron et al. [24] reported a $33 \mathrm{~mL}$ (95\% CI -36.3 to $-31.3 \mathrm{~mL}$ ) reduction in FEV1, although air pollution levels were generally lower than those in the two aforementioned studies. The authors attribute the stronger estimates to the large sample size, harmonised spirometer use and protocols, and reduced air pollution exposure misclassification [24]. Estimates for $\mathrm{NO}_{2}$ reported by Doiron et al. [24], however, are comparable to those reported by Forbes et al. [12] ( $-32 \mathrm{~mL}$, $95 \% \mathrm{CI}-39$ to $-24 \mathrm{~mL}$, per $10 \mu \mathrm{g} \cdot \mathrm{m}^{-3}$ increase in $\mathrm{NO}_{2}$ ) from another British study that did not use ESCAPE LUR models, but air dispersion models for air pollution exposure assessment.

Determining susceptible subgroups within the population is important for developing targeted interventions to reduce the respiratory disease burden. Therefore, the assessment of potential subgroups with increased susceptibility to the adverse effects of air pollution on lung function and COPD by DoIRON et al. [24] presents an interesting perspective. The extraordinary large sample size, ensuring sufficient statistical power to conduct subgroup analyses, is a major strength of this study over previous studies. The stronger associations of air pollution exposure with lower lung function in subjects with a lower income and obese individuals were in line with findings of previous studies [15, 25]. Associations between air pollution and lung function were found to be stronger in males, while associations between air pollution and COPD were stronger in females [24]. Current evidence on sex as a modifier of the association between air pollution and lung function is mixed. A review of the role of sex in air pollution epidemiology concluded that in later childhood, adolescence and adulthood, effects tended to be stronger for females than for males, while effects tended to be stronger for boys in early life [26]. However, a more recent review reported uncertainty around evidence for sex effect modification of air pollution effects on lung function in childhood [4].

Of particular interest are also the subgroup analyses by occupation presented by Dorron et al. [24], as not many studies have the statistical power to reliably assess this effect modification. Significant associations with lower lung function, but not with risk of COPD were found for participants with current employment in one out of 14 jobs with an increased risk of COPD, compared to participants with other occupations. The authors argue that the lack of effect modification by occupation for COPD might be attributable to a healthy worker effect, i.e. participants with COPD being less likely to work in high risk occupations. The lack of data on occupational history hinders further considerations regarding duration of occupation and past occupations. However, supportive evidence comes from another study that has investigated a similar effect modification in relation to mortality and has reported a higher relative risk of death in relation to air pollution exposure among participants exposed to dust or fumes in the workplace [27]. More studies with adequate data are required to explore and contribute to these findings.

Despite the impressive sample size, objective spirometry measurements, and standardised exposure assessment, there are some limitations to the work by DoIRON et al. [24]. Firstly, the cross-sectional nature of the study limits the ability to establish temporal causal links of air pollution exposure with lung function and COPD in this study. Also, it is uncertain whether the lower adult lung function and higher risk of COPD are the result of changes in lung development during childhood that resulted in lower maximum achieved lung function in early adulthood and persisted into adulthood [28], or the result of an accelerated age-related decline in lung function during adulthood, as suggested by some studies [13, 14, 16]. Continued follow-up of spirometry measurements from the UK Biobank cohort could provide important contributions to the knowledge gap regarding age-related decline.

The assessment of the consequences of air pollution effects on children's lungs for later COPD development remains challenging. Not many birth and child cohorts currently have sufficiently long follow-ups to assess life-course associations of air pollution with lung function and COPD from childhood 
through adolescence into adulthood. However, several cohort studies with detailed lung function data and exposure histories from childhood are well on their way but will need few more decades to assess the impact of air pollution on lung function and COPD through the course of life. Another potential limitation of the study by DOIRON et al. [24] concerns air pollution exposure assessment. LUR models developed for the Thames Valley region were transferred to the UK Biobank study areas to predict air pollution concentrations. Transferability of the LUR models may be a source of measurement error as it has been shown that models tend to perform less well outside the Thames Valley region and prior to 2007 [29], and therefore bias cannot be ruled out. Furthermore, Doiron et al. [24] did not account for spatial autocorrelation of observations, which may have introduced additional bias.

The Air Quality Pollutant Inventories report for England, Scotland, Wales and Northern Ireland recently reported that, as of 2017, UK air quality was much better than at any time since the industrial revolution [30]. However, this study by Dorron et al. [24], one of the largest to date to examine associations of air pollution exposure and lung function and COPD in adults, still demonstrates adverse effects even at declining air pollution levels. This presents important evidence that can inform policy making, highlighting the necessity for more comprehensive efforts in reducing air pollution and the need to mitigate the burden of air pollution on respiratory health.

Conflict of interest: E.B. Milanzi has nothing to disclose. U. Gehring has nothing to disclose.

\section{References}

1 Health Effects Institute. State of Global Air 2019. 2019. www.stateofglobalair.org/sites/default/files/soga_2019_ report.pdf Date last accessed: June 6, 2019.

2 Cohen AJ, Brauer M, Burnett R, et al. Estimates and 25-year trends of the global burden of disease attributable to ambient air pollution: an analysis of data from the Global Burden of Diseases Study 2015. Lancet 2017; 389: $1907-1918$.

3 United States Environmental Protection Agency. 2009 Final Report: Integrated Science Assessment for Particulate Matter. 2009. https://cfpub.epa.gov/ncea/risk/recordisplay.cfm?deid=216546 Date last accessed June 6, 2019.

4 Schultz ES, Litonjua AA, Melen E. Effects of long-term exposure to traffic-related air pollution on lung function in children. Curr Allergy Asthma Rep 2017; 17: 41.

5 Rosenlund M, Forastiere F, Porta D, et al. Traffic-related air pollution in relation to respiratory symptoms, allergic sensitisation and lung function in schoolchildren. Thorax 2009; 64: 573-580.

6 Mudway IS, Dundas I, Wood HE, et al. Impact of London's low emission zone on air quality and children's respiratory health: a sequential annual cross-sectional study. Lancet Public Health 2019; 4: e28-e40.

7 Gauderman WJ, Avol E, Gilliland F, et al. The effect of air pollution on lung development from 10 to 18 years of age. N Engl J Med 2004; 351: 1057-1067.

8 Milanzi EB, Koppelman GH, Smit HA, et al. Air pollution exposure and lung function until age 16: the PIAMA birth cohort study. Eur Respir J 2018; 52: 1800218.

9 Schultz ES, Hallberg J, Bellander T, et al. Early-life exposure to traffic-related air pollution and lung function in adolescence. Am J Respir Crit Care Med 2016; 193: 171-177.

10 Ackermann-Liebrich U, Leuenberger P, Schwartz J, et al. Lung function and long term exposure to air pollutants in Switzerland. Study on Air Pollution and Lung Diseases in Adults (SAPALDIA) Team. Am J Respir Crit Care Med 1997; 155: 122-129.

11 de Jong K, Vonk JM, Zijlema WL, et al. Air pollution exposure is associated with restrictive ventilatory patterns. Eur Respir J 2016; 48: 1221-1224.

12 Forbes LJ, Kapetanakis V, Rudnicka AR, et al. Chronic exposure to outdoor air pollution and lung function in adults. Thorax 2009; 64: 657-663.

13 Downs SH, Schindler C, Liu LJ, et al. Reduced exposure to PM10 and attenuated age-related decline in lung function. N Engl J Med 2007; 357: 2338-2347.

14 Guo C, Zhang Z, Lau AKH, et al. Effect of long-term exposure to fine particulate matter on lung function decline and risk of chronic obstructive pulmonary disease in Taiwan: a longitudinal, cohort study. Lancet Planet Health 2018; 2: e114-e125.

15 Adam M, Schikowski T, Carsin AE, et al. Adult lung function and long-term air pollution exposure. ESCAPE: a multicentre cohort study and meta-analysis. Eur Respir J 2015; 45: 38-50.

16 Huls A, Sugiri D, Abramson MJ, et al. Benefits of improved air quality on ageing lungs: impacts of genetics and obesity. Eur Respir J 2019; 53: 1801780.

17 Postma DS, Rabe KF. The asthma-COPD overlap syndrome. N Engl J Med 2015; 373: 1241-1249.

18 Viegi G, Pistelli F, Sherrill DL, et al. Definition, epidemiology and natural history of COPD. Eur Respir J 2007; 30: 993-1013.

19 World Health Organization. COPD Predicted to be Third Leading Cause of Death in 2030. www.who.int/ respiratory/copd/World_Health_Statistics_2008/en/ Date last accessed: May 10, 2019.

20 Postma DS, Bush A, van den Berge M. Risk factors and early origins of chronic obstructive pulmonary disease. Lancet 2015; 385: 899-909.

21 Schikowski T, Mills IC, Anderson HR, et al. Ambient air pollution: a cause of COPD? Eur Respir J 2014; 43: 250-263.

22 Liu S, Zhou Y, Liu S, et al. Association between exposure to ambient particulate matter and chronic obstructive pulmonary disease: results from a cross-sectional study in China. Thorax 2016; 72: 788-795.

23 Fang L, Gao P, Bao H, et al. Chronic obstructive pulmonary disease in China: a nationwide prevalence study. Lancet Respir Med 2018; 6: 421-430. 
24 Doiron D, de Hoogh $\mathrm{K}$, Probst-Hensch N, et al. Air pollution, lung function and COPD: results from the population-based UK Biobank study. Eur Respir J 2019; 54: 1802140.

25 Doiron D, de Hoogh K, Probst-Hensch N, et al. Residential air pollution and associations with wheeze and shortness of breath in adults: a combined analysis of cross-sectional data from two large european cohorts. Environ Health Perspect 2017; 125: 097025.

26 Clougherty JE. A growing role for gender analysis in air pollution epidemiology. Environ Health Perspect 2010; 118: $167-176$.

27 Krewski D, Burnett RT, Goldberg M, et al. Reanalysis of the Harvard Six Cities Study, part II: sensitivity analysis. Inhal Toxicol 2005; 17: 343-353.

28 Fuertes E, Bracher J, Flexeder C, et al. Long-term air pollution exposure and lung function in 15 year-old adolescents living in an urban and rural area in Germany: The GINIplus and LISAplus cohorts. Int J Hyg Environ Health 2015; 218: 656-665.

29 Gulliver J, de Hoogh K. Environmental exposure assessment: modelling air pollution concentrations. In: Detels R, Gulliford M, Karim AQ, Chuan C, eds. Oxford Textbook of Global Public Health. 6th Edn. Oxford, Oxford University Press, 2015.

30 Balakrishnan VS. UK air pollution declines but more needs to be done. Lancet Respir Med 2017; 5: 928. 